\title{
Negative Pressure Wound Therapy Versus Conventional Dressing in Treatment of Diabetic Foot Wound Atef Bayoumi, Abdullah Al-Sayed, Abdullah Al-Mallah
}

Vascular Surgery Department - Faculty of Medicine - Al-Azhar University - Cairo - Egypt

Corresponding Author: Abdullah Al-Mallah, Email: poet.abdullah2009@ gmail.com

\begin{abstract}
Background: Foot wounds in people with diabetes mellitus are a common and serious global health issue. Negative pressure wound therapy can be used to treat these wounds and a clear and current overview of current evidence is required to facilitate decision-making regarding its use. Aim of the Work: To compare the efficacy of negative pressure wound therapy with that of a control group using conventional moist wound dressings, in healing of diabetic foot ulcers, in terms of 1) Change in size of wound. 2) Rate of granulation tissue formation as percentage of ulcer surface area. 3) Period of hospital stay. 4) Cost of both modalities of treatment. And 5) Complications after treatment. Study Design: Prospective Randomized Controlled Trial. Place: This study was conducted in the vascular surgery department at Al-Azhar university hospitals. Methodology: The study included 50 patients randomized into two groups ( 25 patient for VAC therapy \& 25 patient for conventional dressing) suffering from diabetic foot wounds. Results: In our study, 6 of 25 (24\%) in the Conventional treatment group were females whereas 19 of $25(76 \%)$ in the Conventional treatment group were males. 3 of $25(12 \%)$ in the NPWT group were females and 22 of $25(88 \%)$ were males. In the Conventional treatment group, 21 of 25 (84\%) were above 60 years of age. 20 of 25 (80\%) in the NPWT group were above 60 years of age. Wound bed showed signs of healing by granulation tissue formation in 19 among 25 patients $(76 \%)$ compared to Conventional treatment, 7 showed granulation among 25 patients $(28 \%)$ one week after initiation of treatment. $(\mathrm{P}=0.001)$. Granulation of the wounds was $>50 \%$ in 20 of the 25 patients underwent NPWT whereas only 3 of the 25 in the Conventional treatment had shown $>50 \%$ granulation. There was a highly statistically significant difference between average Granulation as \% of ulcer area and it is significantly high in vacuum dressing. It was $51.92 \pm 21.03$ in Conventional treatment compared with $78.68 \pm$ 18.12 in NPWT group ( $\mathrm{p}$ - value < 0.05). Wound size was measured at initial presentation and then after treatment. Before treatment, the mean surface area of wounds in the NPWT group was $40.44 \mathrm{~cm} 2$, the Conventional treatment $38.52 \mathrm{~cm} 2$. After wound management, mean surface area of the diabetic wounds was $36.08 \pm 2.56 \mathrm{~cm} 2$ in the NPWT group and $37.63 \pm 2.86 \mathrm{~cm} 2$ in the Conventional treatment. This represents a statistically significant difference $(\mathrm{P}=0.05)$. At the end of our study the incidence of secondary higher amputation in NPWT group was 5/25 (20\%), the Conventional treatment 6/25 (24\%). There was no significant difference between both groups $(\mathrm{P}=0.13)$. There is a statistically significant difference between average graft take-up and it is higher in vacuum dressing. It was $80.78 \pm 14.54$ in NPWT and 59.58 \pm 19.25 in control group. $(\mathrm{P}$-value $=0.035)$. Daily mean cost in conventional dressing group was $67.43 \pm 5.3 \mathrm{EP}$ compared to $95.7 \pm$ 10.2 EP in VAC group. A difference which is statistically different. Also, at the end of the study, total mean cost in conventional dressing group was $1976 \pm 123 \mathrm{EP}$ compared to $2275 \pm 154 \mathrm{EP}$ in VAC group. There was a difference in the total cost finally. Period of hospital stay till the wound was fully granulated and ready for skin grafting was $22.87 \pm 7.62$ in NPWT compared to $32.53 \pm 10.17$ in the conventional group. There is a highly statistically significant difference between average duration of hospital stay and it is reduced significantly in vacuum dressing. ( $\mathrm{p}$-value $=0.02$ ). Conclusion: The rate of granulation tissue formation, wound surface area, overall graft survival was better in NPWT group as compared to conventional dressing group. Overall hospital stay and amputation rate were less in the NPWT group. Thus, NPWT can be considered as a superior option in the management of diabetic foot wounds. Cost of VAC therapy was higher than conventional dressing.
\end{abstract}

Key Words: Diabetes - Foot Ulcer - Vacuum Assisted Closure - Negative Pressure Wound Therapy

\section{INTRODUCTION}

Foot wounds in people with diabetes mellitus (DM) are a common and serious global health issue. Negative pressure wound therapy can be used to treat these wounds and a clear and current overview of current evidence is required to facilitate decision-making regarding its use ${ }^{(1)}$.

As a new generation of negative pressure drainage technology, vacuum-assisted closure
(VAC) can provide stable and persistent negative pressure, and there are several modes to choose from. VAC plays an important role in closing wounds quickly, controlling infection, promoting angiogenesis, increasing blood flow, and promoting granulation tissue growth of wounds. It is now widely applied in all kinds of acute, chronic, and special wounds in clinic with good therapeutic results. However, we need to pay 
attention to contraindications and complications of VAC when it is used, avoiding secondary damage due to improper treatment ${ }^{(2)}$.

Topical negative pressure (TNP) therapy is widely used in the treatment of acute wounds in vascular patients on the basis of proposed multifactorial benefits. However, numerous recent systematic reviews have concluded that there is inadequate evidence to support its benefits at a scientific level ${ }^{(3)}$.

In course of treatment of diabetic foot with ischemic origin, beyond effective medical treatment revascularization (open vascular surgery or endovascular procedures) has paramount importance for prevention of limb loss ${ }^{(4)}$.

VAC therapy, together with debridement and appropriate antibiotic therapy, enables a higher rate of limb salvage ${ }^{(5)}$.

Recent studies have shown that application of a sub atmospheric pressure in a controlled manner to the wound site has got an important role in assisting wound healing ${ }^{(2)}$.

The present study was conducted to assess the efficacy of vacuum assisted closure dressings as compared to conventional moist wound dressings in improving the healing process in diabetic foot wounds.

\section{PATIENTS AND METHODS}

Patients: This prospective randomized comparative study was conducted in the vascular surgery department at Al-Azhar university hospitals. The study included 50 patients randomized into two groups (25 patient for VAC therapy \& 25 patient for conventional dressing) suffering from diabetic foot wounds. Satisfying all the inclusion criteria mentioned below, after the clearance from the ethical committee was obtained. All chronic wounds where conventional dressings are indicated were included in the study. Inclusion criteria: Patients with age between 12 75 years, Diabetic Foot wounds, Wound size $>2 \mathrm{~cm} 2$ and patients giving consent for either types of treatment vacuum therapy or ordinary dressing. Exclusion criteria: Untreated underlying osteomyelitis, Exposed arteries or veins Malignancy within wounds, Dry gangrene, Wounds resulting from electrical, chemical, or radiation burns and those with collagen vascular disease. Methods: 50 patients randomly divided into two groups. Group A (patients treated with VAC) and Group B (patients treated with conventional dressings). All patients underwent detailed clinical examination and relevant investigations and the wounds were thoroughly debrided and the ulcer dimensions as well as the surface area was assessed. Before the start of VAC therapy, after initial debridement, the wound was photographed with a ruler placed beside the wound. A double layer of polyethylene sheets was held firmly in place over the wound, and an outline of the wound was traced using a permanent marker. The layer in direct contact with the wound was discarded. At VAC dressing changes, the wound was photographed and measured. Before surgical intervention at the end of VAC therapy, the final appearance of the wound was again noted and recorded.

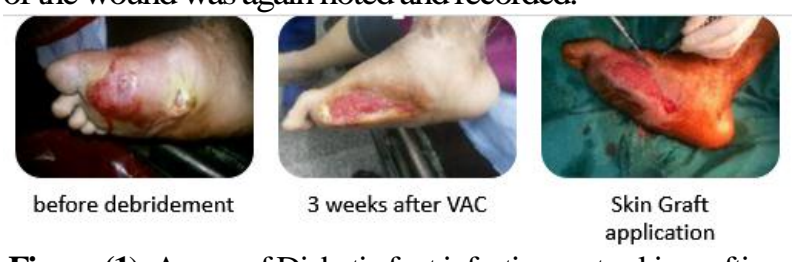

Figure (1): A case of Diabetic foot infection up to skin grafting.

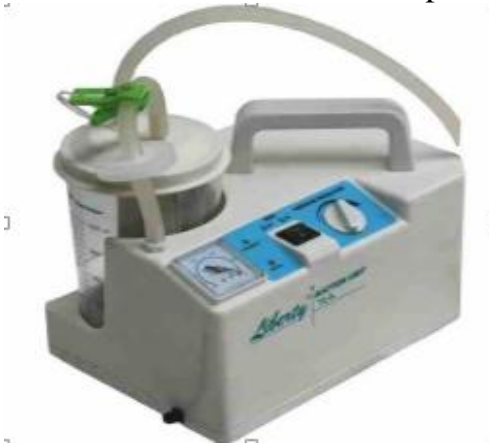

Figure (2): In our study, this modified set was used for negative pressure wound therapy.

Follow up and assessments:

Patients were followed up after 1 week (for detection of early granulation tissue formation), 3 weeks (for wound size measurement) and 3 months later (for detection of any complications e.g. Amputation). The results obtained were statistically evaluated by SPSS 20 . The study was approved by the Ethics Board of Al-Azhar University.

\section{RESULTS}

6 of 25 (24\%) in the Conventional treatment were females whereas 19 of $25(76 \%)$ in the Conventional treatment were males. 3 of $25(12 \%)$ in the NPWT group were females and 22 of 25 (88\%) were males.

Out of all patients under study, no one had type I DM, all of them had type II DM. Mean duration of diabetes presentation was $12.82 \pm 5.66$ and $13.69 \pm 5.42$ years in conventional and NPWT groups, respectively $(\mathrm{p}=0.67)$.

Right lower limb was involved in $64 \%$ of NPWT group of patients while same limb was affected in $80 \%$ patients who received Conventional treatment. No statistical difference was found. $(\mathrm{P}$-value $=0.15$ ). 
Majority of the patients in both treatment groups had hypertension, ischemic heart disease and neuropathy while nephropathy was present in only one patient resulting from septicemia. The difference of comorbid condition was not statistically significant in both groups (P-value $>0.05$ ).

Patients of both groups were classified according to Wagner's grading system. Majority of patients had Wagner's grade 2 ulcer (60\% in Conventional group and $72 \%$ in NPWT group, $\mathrm{P}=0.28$ ).

Wound bed granulation one week after treatment:

The use of NPWT may be an effective initial wound therapy to achieve faster wound bed granulation showing signs of healing in 19 among 25 patients $(76 \%)$ compared to Conventional treatment 7 showed granulation among 25 patients $(28 \%)$ one week after treatment. $(\mathrm{P}=0.001)$.

Granulation tissue formation at the end of the study:

Mean percent of granulation tissue formed:

There is a highly statistically significant difference between average granulation in $\%$ of ulcer area and it is significantly high in vacuum dressing.

Table (1): Comparison of Granulation as \% of ulcer area Mean \pm SD Between Study And Control Group

\begin{tabular}{|c|c|c|c|c|c|}
\hline \multirow{2}{*}{$\begin{array}{c}\text { Granulation } \\
\text { as \% of } \\
\text { ulcer area }\end{array}$} & \multicolumn{2}{|c|}{$\begin{array}{c}\text { Conventional } \\
\text { dressing }\end{array}$} & \multicolumn{2}{|c|}{ NPWT } & \multirow{2}{*}{$\begin{array}{c}\text { P- } \\
\text { value }\end{array}$} \\
\cline { 2 - 5 } & Mean & SD & Mean & SD & \\
\cline { 2 - 5 } & 51.92 & 21.03 & 78.68 & 18.12 & 0.0001 \\
\hline
\end{tabular}

Mean surface area of wounds

Wound size was measured at initial presentation and then after treatment. Our main end point of wound healing/reduction in size was compared in both groups using Chi-square test. Before treatment, the mean surface area of wounds in the NPWT group was $40.44 \mathrm{~cm} 2$, the Conventional treatment $38.52 \mathrm{~cm} 2$. After wound management, mean surface area of the diabetic wounds was 36.08 $\pm 2.56 \mathrm{~cm} 2$ in the NPWT group and $37.63 \pm 2.86$ $\mathrm{cm} 2$ in the Conventional treatment. This was a statistically significant difference $(\mathrm{P}<0.05)$.

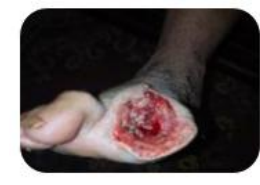

After Amputation

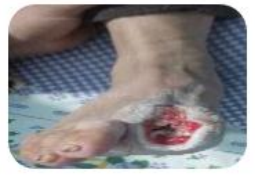

1 week after VAC

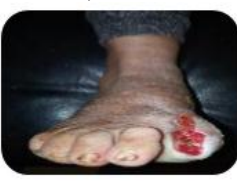

3 weeks later
Figure (3): Decreased wound surface area after VAC therapy.

Table (2): Mean surface area $(\mathrm{cm} 2)$ of the wounds.

\begin{tabular}{|c|c|c|c|}
\hline Wound size & $\begin{array}{c}\text { Conventional } \\
\text { treatment }\end{array}$ & NPWT & $\begin{array}{c}\text { p- } \\
\text { value }\end{array}$ \\
\hline Initial size in $\mathrm{cm} 2$ & $38.52 \pm 2.73$ & $40.44 \pm 2.82$ & $<0.05$ \\
After treatment & $37.63 \pm 2.86$ & $36.08 \pm 2.56$ & \\
\hline
\end{tabular}

\section{Incidence of 2ry higher amputation:}

The incidence of secondary higher amputation in NPWT group is 5/25 (20\%), the Conventional treatment 6/25 (24\%). There was no significant difference between both groups $(\mathrm{P}=0.13)$.

\section{Average graft take-up}

There is a highly statistically significant difference between average graft take-up and it is significantly high in vacuum dressing.

Table (3): Comparison of Average graft take-up between Study And Control Group.

\begin{tabular}{|c|c|c|c|}
\hline Parameter & NPWT & $\begin{array}{c}\text { Conventional } \\
\text { dressing }\end{array}$ & P-value \\
\hline $\begin{array}{c}\text { Average graft } \\
\text { take-up }\end{array}$ & $80.78 \pm 14.54$ & $59.58 \pm 19.25$ & 0.035 \\
\hline
\end{tabular}

Difference in cost between the two modalities:

Every patient was asked for the mean cost of the conventional dressing or VAC in both groups respectively.

Cost included price of the used materials (e.g. gauze) and specialist fees.

It was found that the daily mean cost in conventional dressing group was $67.43 \mathrm{EP}$ compared to $95.7 \mathrm{EP}$ in VAC group. A difference which is statistically different.

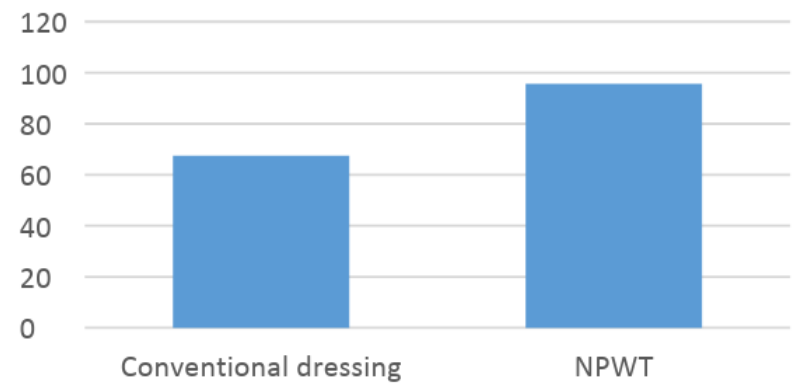

Figure (4): Comparison of Average cost Between Study And Control Group

\section{Hospital stay:}

Period of hospital stay till the wound was fully granulated or ready for skin grafting was 22.87 \pm 7.62 in NPWT compared to $32.53 \pm 10.17$ in the conventional group.

Table (4): Comparison of Average time for hospital stay Between Study And Control Group.

\begin{tabular}{|c|c|c|c|}
\hline Hospital stay: & NPWT & $\begin{array}{c}\text { Conventional } \\
\text { dressing }\end{array}$ & $\begin{array}{c}\text { p- } \\
\text { value }\end{array}$ \\
\hline $\begin{array}{c}\text { Average period } \\
\text { (days) }\end{array}$ & $22.87 \pm 7.62$ & $32.53 \pm 10.17$ & 0.02 \\
\hline
\end{tabular}


There is a highly statistically significant difference between average duration of hospital stay and it is reduced significantly in vacuum dressing.

\section{Total cost of both therapies combined with} Hospital stay:

It was found that the total mean cost in conventional dressing group was $1976 \pm 123 \mathrm{EP}$ compared to $2275 \pm 154 \mathrm{EP}$ in VAC group. There was a difference in the total cost finally.

Being higher in cost, VAC therapy although has a shorter hospital stay and faster healing time in comparison with conventional dressing.

\section{DISCUSSION}

Out of the top 10 countries with the highest prevalence rates of diabetic foot ulcers, six are Arab countries and almost 20.5 million people in that part of the world live with diabetes. The mean prevalence of DFU in Egypt is $4.2 \%$ according to ${ }^{(6)}$.

Egypt is the only Arab country on the list of the top ten countries that have the largest number of diabetic patients as it occupies the ninth position on the list with a total number of 7.3 million diabetics in 2011 and that number is expected to increase to reach 12.4 million by year $2030^{(7)}$.

Diabetic foot problems are the commonest reason for hospitalization of diabetic patients (about $30 \%$ of admissions) and absorb some $20 \%$ of the total health-care costs of the disease more than all other diabetic complication ${ }^{(8)}$.

Foot ulceration is common, affecting up to $25 \%$ of patients with diabetes during their lifetime. Over $85 \%$ of lower limb amputations are preceded by foot ulcers and diabetes remains a major cause of non-traumatic amputation across the world with rates being as much as 15 times higher than in the nondiabetic population ${ }^{(8)}$.

Negative pressure wound therapy (NPWT) is one of the most important treatments for diabetic foot ulcers ${ }^{(9)}$.

Little work is done on the effect of VAC therapy in the management of DFU in Egypt so far. VAC therapy was studied by some Egyptian authors like ${ }^{(10,11,12)}$ and additional study from Suez Canal University ${ }^{(13)}$. Theses studies from Mansoura University, Tanta University and Cairo University all concluded that Negative Pressure Wound Therapy was found to facilitate rapid granulation tissue formation and shorten healing time of the lower limb ulcers.
Our study proved the hypothesis that NPWT is more efficacious than conventional treatment for the treatment of DFU. In our study, 6 of 25 (24\%) in the Conventional treatment group were females whereas 19 of $25(76 \%)$ in the Conventional treatment group were males. 3 of $25(12 \%)$ in the NPWT group were females and 22 of $25(88 \%)$ were males. In the Conventional treatment group, 4 of $25(16 \%)$ were at age of 60 or below and $84 \%$ were above 60 years of age. 5 of $25(20 \%)$ in the NPWT group were at or below 60 years and $80 \%$ were above 60 years of age. Wound bed showed signs of healing by granulation tissue formation in 19 among 25 patients (76\%) compared to Conventional treatment, 7 showed granulation among 25 patients $(28 \%)$ one week after initiation of treatment $(\mathrm{P}=0.001)$. Granulation of the wounds was $>50 \%$ in 20 of the 25 patients underwent NPWT whereas only 3 of the 25 in the Conventional treatment had shown $>50 \%$ granulation.

There was a highly statistically significant difference between average Granulation as \% of ulcer area and it is significantly high in vacuum dressing. It was $51.92 \pm 21.03$ in Conventional treatment compared with $78.68 \pm 18.12$ in NPWT group (p-value $<0.05$ ).

On this point, Paola et al. demonstrated that treating DFU with VAC therapy results in a faster wound bed preparation $(\mathrm{p}=0.03)$, a faster closure $(\mathrm{p}=0.005)$ when compared to standard wound care ${ }^{(14)}$.

Wound size was measured at initial presentation and then after treatment. Before treatment, the mean surface area of wounds in the NPWT group was $40.44 \mathrm{~cm} 2$, the Conventional treatment $38.52 \mathrm{~cm} 2$. After wound management, mean surface area of the diabetic wounds was 36.08 $\pm 2.56 \mathrm{~cm} 2$ in the NPWT group and $37.63 \pm 2.86$ $\mathrm{cm} 2$ in the Conventional treatment. This represents a statistically significant difference $(\mathrm{P}=0.05)$.

A significant shrinkage of wound area $(\mathrm{p}<$ 0.05) was observed over a period of 16 days in a study performed by Kilic et al. ${ }^{(15)}$ Other studies carried out by Dzieciuchowicz et al. ${ }^{(16)}$ Sepulveda et al. ${ }^{(17)}$ Moues et al. ${ }^{(18)}$ and Ubbink et al. ${ }^{(19)}$ found that NPWT is superior to conventional gauze dressings in decreasing wound dimensions, achieving complete wound healing, wound bed preparation at a faster rate and lower incidence of re-amputations.

These results are comparable to data of Chiang et $\boldsymbol{a l} .{ }^{(3)}$ which resulted in no significance in the primary outcome of wound volume reduction between NPWT and control patients on day 14 (44.2\% and $20.9 \%$, 
respectively; $\mathrm{P}=0.15$ ). Analyses of secondary outcomes showed a significant result of better healing rates in the NPWT group by demonstrating a reduction in maximum wound depth at day 14 (36.0\% NPWT vs. $17.6 \%$ control; $\mathrm{P}=0.03)^{(3)}$.

Also these results are comparable to data quoted worldwide. A RCT, conducted by Blume et al. in 2008, revealed that greater proportion of foot ulcers achieved complete ulcer closure with NPWT (43.2\%) than with AMWT (28.9\%) within 112-day active treatment phase $(\mathrm{p}=0.007){ }^{(20)}$.

Note that the data from Blume's study was analyzed by the company funding the study. This may be perceived as a potential source of bias, it is more reassuring to the reader when the data is analyzed by a neutral third party ${ }^{(21)}$.

At the end of our study the incidence of secondary higher amputation in NPWT group was $5 / 25$ (20\%), the Conventional treatment 6/25 (24\%). There was no significant difference between both groups $(\mathrm{P}=0.13)$.

There is a statistically significant difference between average graft take-up and it is higher in vacuum dressing. It was $80.78 \pm 14.54$ in NPWT and $59.58 \pm 19.25$ in control group. $(\mathrm{P}$-value $=0.035)$

Paola et al. demonstrated that treating DFU with VAC therapy results in a better graft take rate $(p=0.05)$ when compared to standard wound care ${ }^{(14)}$.

In our study, it was found that the daily mean cost in conventional dressing group was $67.43 \pm 5.3$ $\mathrm{EP}$ compared to $95.7 \pm 10.2 \mathrm{EP}$ in VAC group. A difference which is statistically different.

Also, at the end of the study, we found that the total mean cost in conventional dressing group was $1976 \pm 123$ EP compared to $2275 \pm 154 \mathrm{EP}$ in VAC group. There was a difference in the total cost finally.

Being higher in cost, VAC therapy although has a shorter hospital stay and faster healing time in comparison with conventional dressing. As our findings, Gestring found that NPWT systems are more expensive than traditional wound dressings. However, the overall cost of wound care depends upon the frequency of dressing changes, need for skilled nursing care, and duration of treatment ${ }^{(22)}$.

Period of hospital stay till the wound was fully granulated and ready for skin grafting was 22.87 \pm 7.62 in NPWT compared to $32.53 \pm 10.17$ in the conventional group. There is a highly statistically significant difference between average duration of hospital stay and it is reduced significantly in vacuum dressing $(\mathrm{P}$-value $=0.02)$.

These results provide evidence for effectiveness of NPWT as cited in literature by various authors ${ }^{(18)}$. NPWT now widely applied in all kinds of acute, chronic, and special wounds in clinic with good therapeutic results ${ }^{(2)}$.

The number of publications on NPWT has grown significantly since the inception of NPWT. In part, this reflects the variations of NPWT that have developed. However, a greater number of robust, randomized, prospective studies are needed to support its widespread use ${ }^{(23)}$.

Clinicians should consider negative pressure wound therapy as an adjunct to other modalities in an effort to avoid complications.

\section{CONCLUSION}

NPWT using VAC is more efficacious than conventional therapy in the management of foot ulcers in diabetic patients. Hospitals should consider VAC therapy set as an essential modality for diabetic foot wound management.

\section{REFERENCES}

1. Dumville J, Hinchliffe $\mathrm{R}$, Cullum $\mathrm{N}$ et al. (2013): Negative pressure wound therapy for treating foot wounds in people with diabetes mellitus. Cochrane Database of Systematic Review, (10). doi: 10.1002/ 14651858. CD010318

2. Xie S, Guo G, Min D (2017): Advances in the research of application of vacuum-assisted closure in wound healing and its mechanism. Chinese journal of burns, 33(6): 397-400.

3. Chiang N, Rodda O, Sleigh $\mathbf{J}$, Vasudevan $\mathbf{T}$ (2017): Effects of topical negative pressure therapy on tissue oxygenation and wound healing in vascular foot wounds. Journal of vascular surgery, 66(2):564-571.

4. Kolossváry E, Bánsághi Z, Szabó G, Járai Z et al. (2017): Ischemic origin of diabetic foot disease. Epidemiology, difficulties of diagnosis, options for prevention and revascularization. Orvosi hetilap., 158(6): 203-211. 
5. Ulusal A, Sahin B, Ulusal B et al. (2011): Negative pressure wound therapy in patients with diabetic foot. Acta Orthop Traumatol Turc., 45(4): 254-260.

6. Mairghani M, Elmusharaf K, Patton et al. (2017): The prevalence and incidence of diabetic foot ulcers among five countries in the Arab world: a systematic review. Journal of wound care, 26(9):S27-S34.

7. Alzahrani O, Badahdah S, Bamakrid S et al. (2013): The Diabetic Foot Research in Arabs' Countries. Open Journal of Endocrine and Metabolic Diseases, 3(03): 157.

8. Williams R, Airey M (2000): The size of the problem: epidemiological and economic aspects of foot problems in diabetes. The foot in diabetes, 34: 3-17.

9. Wang $T$, He $R$, Zhao $J$ et al. (2017): Negative pressure wound therapy inhibits inflammation and upregulates activating transcription factor- 3 and downregulates nuclear factor- $\kappa \mathrm{B}$ in diabetic patients with foot ulcerations. Diabetes/metabolism research and reviews, 33(4): e2871.

10. Mahmoud E (2012): Efficacy of negative pressure wound therapy on lower limb ulcers. CU Theses. URL: https://goo.gl/1su8pG

11. El-Shennawy M, Refaat A (2016): Evaluation of Negative Pressure Wound Therapy in Treatment of chronic Lower Extremity Diabetic Wound. TU Thesis. URL: https://goo.gl/JvJ2yr

12. El-Nagar M (2017): Comparative study between negative pressure wound therapy and platelet rich plasma in neovascularization of chronic wound healing. Thesis. URL: https://goo.gl/sPC93e

13. Ahmed Y (2013): A Comparative Study between Vacuum-assisted Closure (VAC) and PlateletRich Plasma Gel (PRP) in Management of Complex wounds (Clinical Trial) in Suez Canal University Hospital. URL: https://goo.gl/Gj8Whz

14. Dalla P, Carone A, Ricci S et al. (2010): Use of vacuum assisted closure therapy in the treatment of diabetic foot wounds. J Diabetic Foot Complications, 2(2): 33-44..
15. Kilic A, Ozkaya U, Sokucu S et al. (2009): Use of vacuum-assisted closure in the topical treatment of surgical site infections. Acta Orthop Traumatol Turc., 43:336-42.

16. Dzieciuchowicz L, Espinosa G, Grochowicz L (2009): Vacuum assisted closure (VAC) in the treatment of advanced diabetic foot. Cirugía Española (English Edition), 86(4): 213-218.

17. Sepúlveda G, Espíndola M, Maureira M et al. (2009): Negative-pressure wound therapy versus standard wound dressing in the treatment of diabetic foot amputation. A randomised controlled trial. Cirugía Española (English Edition), 86(3): 171-177.

18. Moues CM, Vos MC, van GJ (2004): Bacterial load in relation to vacuum-assisted closure wound therapy: A prospective randomized trial. Wound Repair Regen., 12(1):11-7.

19. Ubbink T, Westerbos $J$, Nelson A et al. (2008): A systematic review of topical negative pressure therapy for acute and chronic wounds. British Journal of Surgery: Incorporating European Journal of Surgery and Swiss Surgery, 95(6): 685-692.

20. Blume PA, Walters J, Payne W (2008): Comparison of negative pressure wound therapy using vacuum-assisted closure with advanced moist wound therapy in the treatment of diabetic foot ulcers: a multicenter randomized controlled trial. Diabetes Care, 31:631.

21. Michael $T$ et al. (2008): Report on Comparison of Negative Pressure Wound Therapy using Vacuum-Assisted Closure with Advanced Moist Wound Therapy in the Treatment of Diabetic Foot Ulcers. The Foot \& Ankle Journal 1 (12): 5 doi: 10.3827/faoj.2008.0112.0005

22. Gestring M, Sanfey H (2014): Negative pressure wound therapy. URL: https://www.uptodate.com/contents/negativepressure-wound-therapy

23. Anghel L, Kim J (2016): Negative-pressure wound therapy: a comprehensive review of the evidence. Plastic and reconstructive surgery, 138(3S): 129S-137S. 